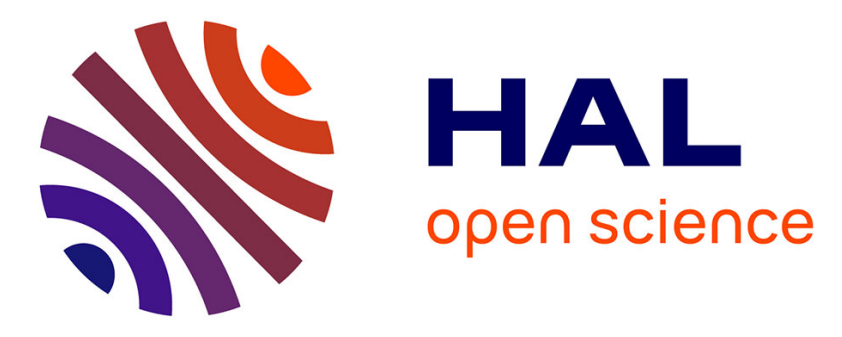

\title{
High efficiency mesoscopic solar cells using CsPbI3 perovskite quantum dots enabled by chemical interface engineering
}

Keqiang Chen, Wei Jin, Yupeng Zhang, Tingqiang Yang, Peter Reiss, Qiaohui Zhong, Udo Bach, Qitao Li, Yingwei Wang, Han Zhang, et al.

\section{To cite this version:}

Keqiang Chen, Wei Jin, Yupeng Zhang, Tingqiang Yang, Peter Reiss, et al.. High efficiency mesoscopic solar cells using CsPbI3 perovskite quantum dots enabled by chemical interface engineering. Journal of the American Chemical Society, 2020, 142, pp.3775-3783. 10.1021/jacs.9b10700 . hal-02492987

\section{HAL Id: hal-02492987 \\ https://hal.science/hal-02492987}

Submitted on 27 Feb 2020

HAL is a multi-disciplinary open access archive for the deposit and dissemination of scientific research documents, whether they are published or not. The documents may come from teaching and research institutions in France or abroad, or from public or private research centers.
L'archive ouverte pluridisciplinaire $\mathbf{H A L}$, est destinée au dépôt et à la diffusion de documents scientifiques de niveau recherche, publiés ou non, émanant des établissements d'enseignement et de recherche français ou étrangers, des laboratoires publics ou privés. 


\section{High efficiency mesoscopic solar cells using $\mathrm{CsPbI}_{3}$ perovskite quantum dots enabled by chemical interface engineering}

Keqiang Chen ${ }^{1,2}$, Wei Jin ${ }^{1}$, Yupeng Zhang ${ }^{2}$, Tingqiang Yang ${ }^{1}$, Peter Reiss ${ }^{3, *}$, Qiaohui Zhong ${ }^{1}$, Udo Bach ${ }^{4}$, Qitao $\mathrm{Li}^{1}$, Yingwei Wang ${ }^{2}$, Han Zhang ${ }^{2}$, Qiaoliang Bao ${ }^{5, *}$, Yueli Liu ${ }^{1, *}$

${ }^{1}$ State Key Laboratory of Silicate Materials for Architectures, School of Materials Science and Engineering, Wuhan University of Technology, Wuhan, 430070, P. R. China

${ }^{2}$ Institute of Microscale Optoelectronics, Collaborative Innovation Centre for Optoelectronic Science \& Technology, Key Laboratory of Optoelectronic Devices and Systems of Ministry of Education and Guangdong Province, College of Physics and Optoelectronic Engineering, Shenzhen Key Laboratory of Micro-Nano Photonic Information Technology, Guangdong Laboratory of Artificial Intelligence and Digital Economy (SZ), Shenzhen University, Shenzhen 518060, P.R. China

${ }^{3}$ Univ. Grenoble-Alpes, CEA, CNRS, IRIG/SyMMES, STEP, 38000 Grenoble, France

${ }^{4}$ Department of Chemical Engineering and ARC Centre of Excellence in Exciton Science, Monash University, Clayton, Victoria 3800, Australia

${ }^{5}$ Department of Materials Science and Engineering and ARC Centre of Excellence in Future Low-Energy Electronics Technologies (FLEET), Monash University, Clayton, Victoria 3800, Australia

Corresponding authors:

[*] Prof. Yueli Liu Tel.: +86-27-87760159

E-mail: 1ylliuwhut@,whut.edu.cn (Yueli LIU)

Prof. Qiaoliang Bao Tel: +61 399054927

Email: qiaoliang.bao@monash.edu (Qiaoliang BAO)

Dr. Peter Reiss Tel: +33438789719

Email: peter.reiss@cea.fr (Peter REISS) 


\begin{abstract}
All-inorganic $\alpha-\mathrm{CsPI}_{3}$ perovskite quantum dots (QDs) are attracting high interest as solar cell absorbers due to their appealing light harvesting properties and enhanced stability due to the absence of volatile organic constituents. Moreover, ex situ synthesized QDs significantly reduce the variability of the perovskite layer deposition process. However, it is highly challenging to incorporate $\alpha-\mathrm{CsPbI}_{3}$ QDs into mesoporous $\mathrm{TiO}_{2}\left(\mathrm{~m}-\mathrm{TiO}_{2}\right)$, which constitutes the best performing electron transport material in state-of-the-art perovskite solar cells. Herein, the $\mathrm{m}-\mathrm{TiO}_{2}$ surface is engineered using an electron-rich cesium-ion containing methyl acetate solution. As one effect of this treatment, the solid-liquid interfacial tension at the $\mathrm{TiO}_{2}$ surface is reduced and the wettability is improved, facilitating the migration of the QDs into m- $\mathrm{TiO}_{2}$. As a second effect $\mathrm{Cs}^{+}$ions passivate the QD surface and promote the charge transfer at the $\mathrm{m}$ $\mathrm{TiO}_{2} / \mathrm{QD}$ interface, leading to an enhancement of the electron injection rate by a factor of three. In combination with an ethanol-environment smoothing route significantly reducing the surface roughness of the $\mathrm{m}-\mathrm{TiO}_{2} / \mathrm{QD}$ layer, optimized devices exhibit highly reproducible power conversion efficiencies exceeding $13 \%$. The best cell with an efficiency of $14.32 \%$ (reverse scan) reaches a short-circuit current density of $17.77 \mathrm{~mA} \mathrm{~cm}^{-2}$, which is an outstanding value for QD-based perovskite solar cells.
\end{abstract}

Keywords: $\alpha-\mathrm{CsPbI}_{3}$ quantum dots; all-inorganic perovskite solar cells; carrier separation and transport; high efficiency; surface treatment; interface engineering 


\section{Introduction}

Colloidal quantum dots (QDs) have received tremendous attention owing to their sizedependent optical, electronic, and surface chemistry properties, which offer exciting additional possibilities with respect to bulk materials. ${ }^{1-4}$ These unique features promote their widespread applications in optoelectronic devices. QD-based solar cells are regarded as a representative candidate for obtaining power conversion efficiencies (PCEs) beyond the Shockley-Queisser limit due to their high potential for multiple exciton generation. ${ }^{5-9}$ Moreover, the ex situ preparation of the active material bears undeniable advantages in terms of device fabrication and reproducibility over the in situ formation and crystallization of thin films during the deposition process. This is particularly true in the case of lead halide perovskite solar cells, as the formation of the perovskite thin film during the spin-coating process is extremely sensitive to even subtle changes in the experimental conditions.

Cubic $\alpha-\mathrm{CsPb}_{3}$, an all-inorganic lead halide perovskite with comparable optoelectronic properties but strongly enhanced stability, is considered to be a very appealing alternative to organic-inorganic hybrid perovskites and a promising light-harvesting material for use in solar cells. ${ }^{10-17}$ Importantly, in form of colloidal QDs the structure could effectively retain the black cubic phase of $\mathrm{CsPbI}_{3}$ (direct band gap of $1.73 \mathrm{eV}$ ), which otherwise easily transforms to the thermodynamically stable orthorhombic $\delta-\mathrm{CsPbI}_{3}$ phase (indirect band gap of $2.82 \mathrm{eV}$ ) in thin film structure. ${ }^{10,18}$ Subsequently, the successful application of this material in planar perovskite solar cells (PSCs) has been demonstrated, reaching very recently PCEs of up to $14.1 \%$, which constitutes the record value reported for QD-based solar cells. ${ }^{12,19-22}$

To achieve high performances, both the optimization of the photoactive material (the perovskite layer) and of the different interfaces (such as the electron transport material (ETM)/perovskite interface, hole transport material (HTM)/perovskite interface) are important. However, the reported $\mathrm{CsPbI}_{3} \mathrm{QD}$-based PSCs are focusing on the surface passivation of $\mathrm{CsPbI}_{3}$ QD films using $\mathrm{Pb}^{2+}$ or $\mathrm{Cs}^{+},{ }^{12,19-22}$ while the potential of chemical interface engineering has 
been largely overlooked. By consequence, low short-circuit current densities $\left(J_{S C},<15 \mathrm{~mA}\right.$ $\mathrm{cm}^{-2}$ ) as compared to hybrid perovskite thin film solar cells have been obtained, restricting the performance of $\mathrm{CsPbI}_{3}$ QD-based PSCs. It is generally assumed that inefficient carrier separation and transport are the principal reasons that limit $J_{S C}$. Especially, extracting electrons is less efficient than extracting holes from perovskites. ${ }^{23-25}$ Therefore, the optimization of the ETM/QDs interface is of paramount importance to promote the electron transfer from the perovskite to the ETM and enhance the $J_{S C}$. So far, the use of mesoscopic $\mathrm{TiO}_{2}\left(\mathrm{~m}-\mathrm{TiO}_{2}\right)$ as an ETM has led to the best performing thin-film PSCs due to the very large developed contact interface with the perovskite, which is conducive to facilitate the carrier separation and transport. ${ }^{26-29}$ This is confirmed by recent studies showing that the electron injection efficiency from $\mathrm{CsPbI}_{3}$ QDs into $\mathrm{m}-\mathrm{TiO}_{2}$ can reach $99 \%$ with an injection rate of up to $2.1 \times 10^{10} \mathrm{~s}^{-1} \cdot{ }^{30}$ However, all-inorganic lead halide QD-based solar cells generally use compact $\mathrm{TiO}_{2}\left(\mathrm{c}-\mathrm{TiO}_{2}\right)$ rather than $\mathrm{m}-\mathrm{TiO}_{2}$ as an ETM as it turns out to be highly challenging to homogeneously incorporate QDs into the mesoporous structure during the short time of the film formation process. ${ }^{12,19,31-32}$ Moreover, the surface roughness of $\mathrm{m}-\mathrm{TiO}_{2}$ films is usually much larger than that of $\mathrm{c}-\mathrm{TiO}_{2}$ films, which leads to the formation of a QD capping layer with irregular structure that negatively impacts the $\mathrm{TiO}_{2} / \mathrm{QD}$ interface properties. Therefore, engineering the ETM layer and the ETM/QDs interface are the key requirements to enhance the carrier separation and photovoltaic properties in $\alpha-\mathrm{CsPbI}_{3}$ QD-based PSCs.

Herein, we demonstrate a novel approach using a solution of cesium acetate (CsOAc) in methyl acetate $(\mathrm{MeOAc})$ for the surface modification of $\mathrm{m}-\mathrm{TiO}_{2}$, which is then applied as an ETM in $\alpha-\mathrm{CsPbI}_{3}$ QD-based PSCs. The Cs-treatment results in significantly improved interface properties enabling effective QD incorporation into the mesoporous $\mathrm{TiO}_{2}$ structure. It is found that the electron injection rate of the Cs-treated $\mathrm{m}-\mathrm{TiO}_{2} / \mathrm{QD}$ interface is about two times higher than that of a $c-\mathrm{TiO}_{2} / \mathrm{QD}$ interface and three times higher than that of an untreated $\mathrm{m}-\mathrm{TiO}_{2} / \mathrm{QD}$ interface. This promotes efficient carrier separation and results in the increase of the $J_{S C}$ and 
PCE values. In combination with an ethanol-environment smoothing route to flatten the m$\mathrm{TiO}_{2} / \mathrm{QDs}$ capping layer at the interface with the HTM, the as-fabricated devices deliver reproducibly efficiencies exceeding $13 \%$, with the best PCE value reaching $14.32 \%$ (reverse scan) combined with an unprecedented high $J_{S C}$ of of $17.77 \mathrm{~mA} \mathrm{~cm}^{-2}$.

\section{Results and Discussion}

$\mathrm{CsPbI}_{3}$ QDs with a diameter of $\sim 9.1 \mathrm{~nm}$ were prepared using a synthesis process similar to that reported by Protesescu et al. (Figure S1b); ${ }^{10}$ synthetic details are given in the Experimental Section. We stress that the purification process is of crucial importance for fabricating high quality QD films. A single washing cycle (methyl acetate/octane) leaves excess ligands on the surface of the QDs, resulting in poor charge transfer and transport properties of the QD film. Moreover, excess ligands might also contribute to the redispersion of existing QD layers during their sequential deposition via spin-coating. Three washing cycles, in turn, lead to an insufficient ligand density on the QD surface and poor colloidal stability. The surface ligand density was calculated according to the TEM and nuclear magnetic resonance (NMR) results, as shown in Figure S1. Therefore, two purifying cycles were used to optimize the surface ligand density of the $\mathrm{CsPbI}_{3}$ QDs. ${ }^{33}$ Concerning the HTM, spiro-OMeTAD dissolved in chlorobenzene (CBZ) (named as CBZ-spiro) is usually used in PSCs. ${ }^{34}$ However, $\mathrm{CsPbI}_{3}$ QDs can be redispersed in $\mathrm{CBZ}$ due to their organic ligand capping, which may induce their solubilization during the HTM deposition. Therefore, methyl acetate (MeOAc) was chosen for the preparation of the spiro $\mathrm{HTM}^{35}$ (as shown in Figure S2, MeOAc-spiro was used as the HTM in all the PSCs except for the device shown in Figure S2a).

Figures $\mathrm{S} 2 \mathrm{~b}$ and $\mathrm{S} 3$ show the $J-V$ characteristics of the $\mathrm{CsPbI}_{3}$ QD-based PSCs using c$\mathrm{TiO}_{2}(\sim 40 \mathrm{~nm})$ and $\mathrm{m}-\mathrm{TiO}_{2}(\sim 200 \mathrm{~nm})$ as the ETM, respectively. It is clear that the $J_{S C}$ and PCE values of the $\mathrm{c}-\mathrm{TiO}_{2}$-based PSCs (c-PSC, $14.44 \mathrm{~mA} \cdot \mathrm{cm}^{-2}, 8.77 \%$ ) are significantly higher than those of the $\mathrm{m}-\mathrm{TiO}_{2}$-based PSCs (m-PSC, $10.07 \mathrm{~mA} \mathrm{~cm}^{-2}, 5.01 \%$ ), which indicates enhanced 
carrier separation and transport in case of the planar structure. We hypothesize that the low performance of the m-PSCs is related to the inefficient QD loading and poorly controlled interface between the $\mathrm{m}-\mathrm{TiO}_{2}$ ETM and $\mathrm{CsPbI}_{3}$ QDs. Figure S4 shows STEM-EDS elemental mapping of the cross-section of the $\mathrm{m}-\mathrm{TiO}_{2} / \mathrm{CsPbI}_{3}$ film. Unsurprisingly, $\mathrm{Cs}, \mathrm{Pb}$, and I were not detected within the $\mathrm{m}-\mathrm{TiO}_{2}$ layer, i.e., $\mathrm{CsPbI}_{3}$ could not incorporate efficiently into the mesoporous $\mathrm{TiO}_{2}$ structure. As a result, all potential advantages of the mesoporous morphology with respect to compact $\mathrm{TiO}_{2}$ are lost.

Chemical interface engineering is a potent way to improve the quality of the boundary between the ETM and the perovskite layer as has been demonstrated in the case of polycrystalline PSCs. There, mainly bifunctional molecules containing carboxylate groups for binding to the $\mathrm{TiO}_{2}$ surface and amine/ammonium groups for hydrogen bonding with the iodine ions of hybrid perovskites have been utilized, resulting in enhanced charge extraction and eventually in improved morphology as well as stability. ${ }^{36-38}$ Here, a novel Cs-treatment procedure is introduced to optimize the interface between $\mathrm{m}-\mathrm{TiO}_{2}$ and $\mathrm{CsPbI}_{3}$ QDs. Briefly, a saturated $\mathrm{MeOAc}$ solution of $\mathrm{CsOAc}$ was spin-coated on the $\mathrm{m}-\mathrm{TiO}_{2}$ film before depositing the $\mathrm{CsPbI}_{3}$ QDs. Figure 1a shows the cross-sectional image of the $\mathrm{FTO} / \mathrm{Cs}-\mathrm{m}-\mathrm{TiO}_{2} / \mathrm{CsPbI}_{3}$ film visualized using high-resolution high-angle annular dark-field (HAADF) scanning transmission electron microscopy (STEM). One can clearly identify the interface between the $\mathrm{CsPbI}_{3}$ QDs (capping layer) and the mesoporous $\mathrm{TiO}_{2}$ film. Moreover, the outline of the $\mathrm{TiO}_{2}$ nanocrystals forming the mesoporous structure and the voids between them disappeared when compared with the pristine $\mathrm{TiO}_{2}$ film (cf. Fig. S4). The high-resolution TEM (HRTEM) image of area 1 in Figure 1a indicates that the $\mathrm{TiO}_{2}$ film is filled with $\mathrm{CsPbI}_{3}$ QDs (Figure 1b) and the Fourier transformation pattern of the $\mathrm{CsPbI}_{3}$ QDs (Figure 1c) further confirms their crystalline structure. The spots can be indexed as (001) and (002) crystal plane reflections from $\alpha-\mathrm{CsPI}_{3}$. STEM-EDS mapping was used to determine the elemental distribution in the Cs-m$\mathrm{TiO}_{2} / \mathrm{CsPbI}_{3}$ film, as shown in Figure 1d. It is clearly visible that, in contrast to the case of 
untreated $\mathrm{m}-\mathrm{TiO}_{2}$ (Figure $\mathrm{S} 4$, atom ratio of $\mathrm{Cs}: \mathrm{Pb}: \mathrm{I}: \mathrm{Ti}: \mathrm{O}$ is 1:1.10:2.94:4.32:11.27), $\mathrm{Cs}, \mathrm{Pb}$, and I are present in significant amounts within the full depth of the $\mathrm{TiO}_{2}$ layer (atom ratio of Cs:Pb:I:Ti:O is 1:1.04:2.85:3.11:9.42). Therefore, we can conclude that $\mathrm{CsPbI}_{3}$ QDs are successfully incorporated into the mesoporous $\mathrm{TiO}_{2}$ structure after Cs-treatment.
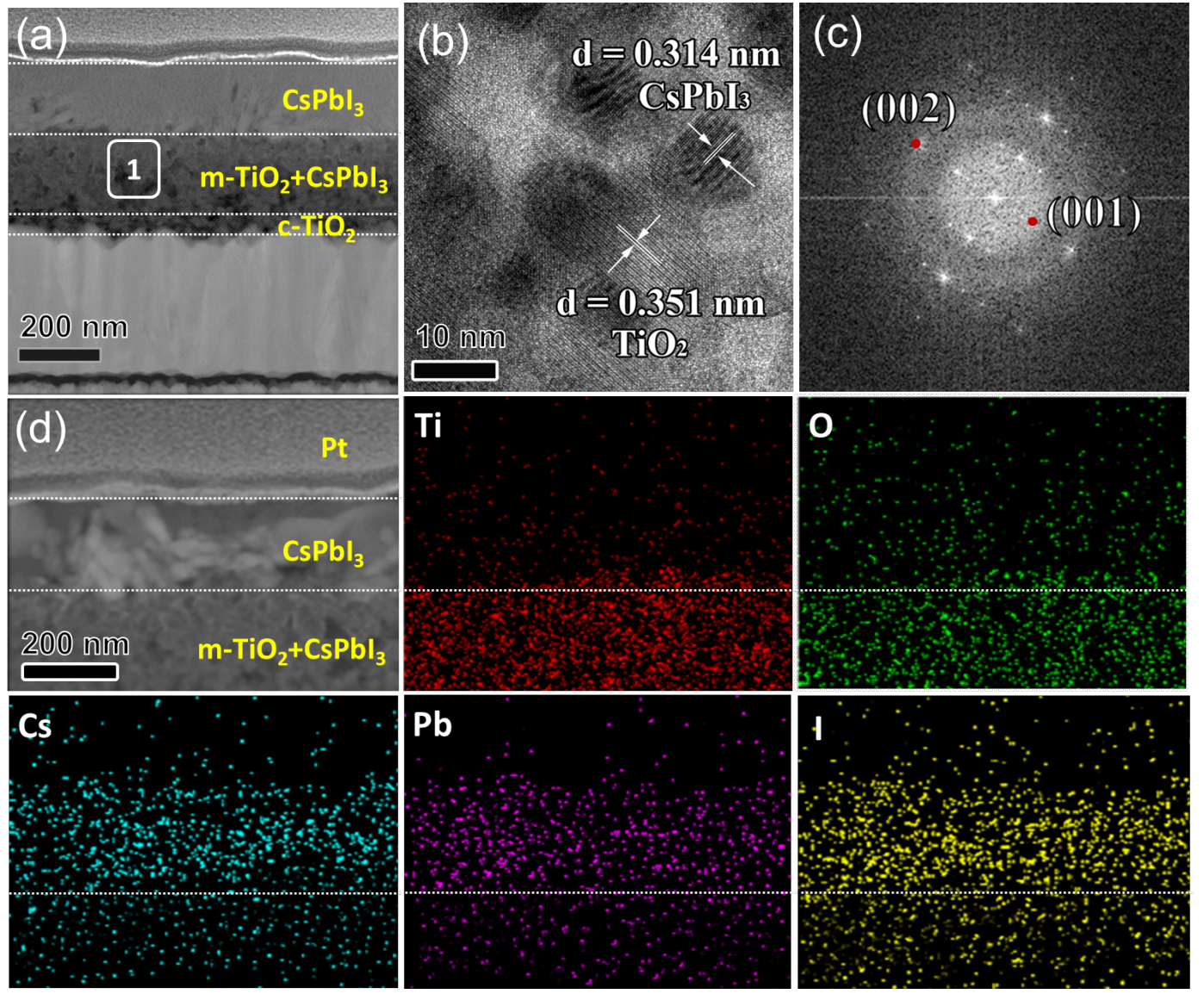

Figure 1. (a) HAADF STEM cross-sectional image of a FTO/Cs-m- $\mathrm{TiO}_{2} / \mathrm{CsPbI}_{3}$ QDs film. (b) HRTEM image from area 1 in (a) demonstrating the presence of $\mathrm{CsPbI}_{3}$ QDs within the

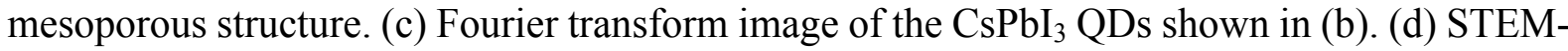
EDS elemental mapping from the cross-section of a Cs-m- $\mathrm{TiO}_{2} / \mathrm{CsPbI}$ film.

The different behavior of Cs-treated $\mathrm{TiO}_{2}$ is ascribed to the synergetic effect from $\mathrm{MeOAc}$ and the surface modification induced by CsOAc. Firstly, as shown in control experiments without $\mathrm{CsOAc}$, MeOAc reduces the surface density of ligands on the QDs (Figure S5a and $\mathrm{S} 5 \mathrm{~b}$ ), which may promote their migration within the mesoporous structure. In addition, water 
contact angle measurements (Figures S5c and S5d) reveal that MeOAc also reduces the solidliquid interfacial tension, which improves the wettability of the $\mathrm{TiO}_{2}$ substrate with the hydrophobic QD colloidal solution. To get further insight into this aspect, density functional theory (DFT) calculations have been performed, as shown in Figure 2. Oxygen atoms on the (001) surface in $\mathrm{TiO}_{2}$ are 2-fold coordinated and electron-deficient. They show a high tendency to adsorb QDs with electron-rich ligands (OA and OLA). The introduction of electron-rich MeOAc passivates the $\mathrm{TiO}_{2}(001)$ surface, thus breaking Ti-O bonds and inducing surface reconstruction (Figures $2 \mathrm{a}$ and $2 \mathrm{~b}$ ). Moreover, the adsorption of OA or OLA will further promote the breaking of Ti-O bonds, as shown in Figures 2c, 2d, and S6. As a result, the adsorption energy $\left(E_{a d s}\right)$ of $\mathrm{OA}$ on the surface of the $\mathrm{TiO}_{2}$ film decreases from $2.29 \mathrm{eV}(2.36 \mathrm{eV}$ for OLA) to $1.02 \mathrm{eV}(1.04 \mathrm{eV})$ after introducing the MeOAc solution. In other words, the surface treatment makes it much easier for QDs to enter into the mesoporous $\mathrm{TiO}_{2}$ structure and to migrate within it.

(a)

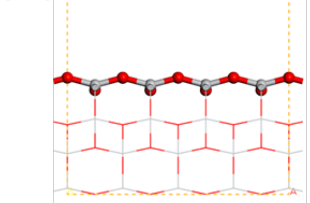

(c)

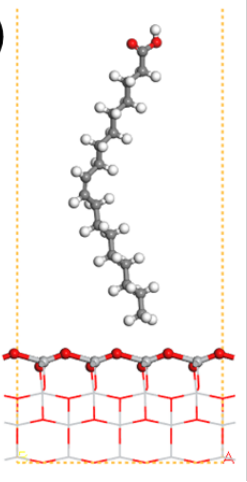

(b)

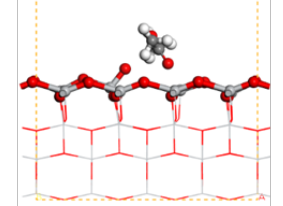

(d)

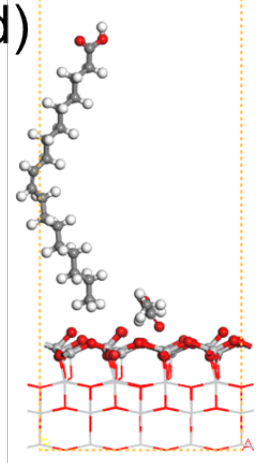

(e)
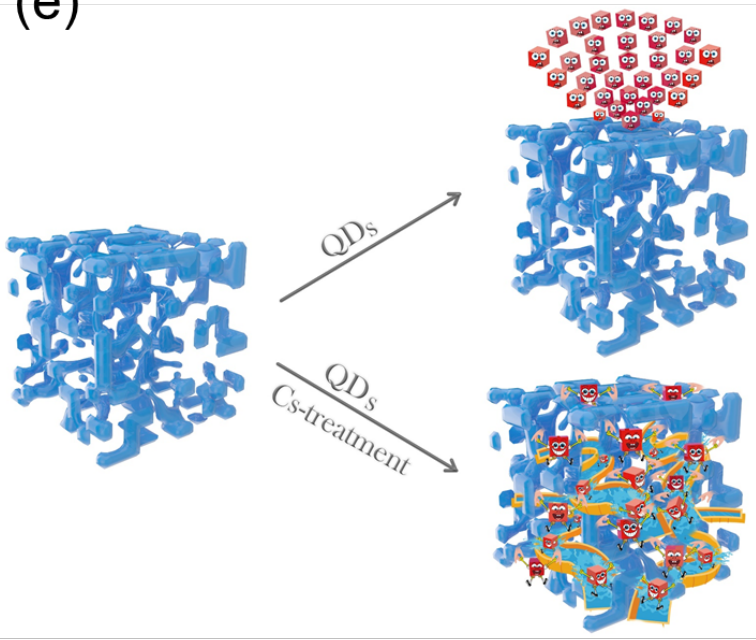

Figure 2. Side view of calculated $\mathrm{TiO}_{2}(001)$ surfaces before (a) and after (b) the exposure to MeOAc, respectively. Chemical structures of OA on a $\mathrm{TiO}_{2}(001)$ surface without (c) and with (d) MeOAc, respectively (atoms at free surface layers and adsorbed molecules are displayed as ball-and-stick models, while the others are displayed as line models). (e) Schematic of QD/ $\mathrm{TiO}_{2}$ mesoporous structure before and after Cs-treatment. 
Secondly, $\mathrm{Cs}^{+}$ions that entered the mesoporous structure with the MeOAc solution can improve the passivation of the QD surface and remove trap states from the QDs, which are known to possess a $\mathrm{PbI}_{2}$-rich surface. ${ }^{10,39}$ In addition, $\mathrm{Cs}^{+}$ions can easily coordinate to the $\mathrm{TiO}_{2}$ surface. Therefore, we hypothesize that these ions also facilitate charge transfer from the QDs to $\mathrm{TiO}_{2}$, which is indirectly demonstrated by comparing the $J-V$ characteristics of PSCs fabricated using MeOAc-modified $\mathrm{m}-\mathrm{TiO}_{2}$ with spin-coating of the QDs, the traditional immersion method (immersing the $\mathrm{TiO}_{2}$ photoanode into the QDs colloidal solution), and $\mathrm{CsOAc} / \mathrm{MeOAc}$-treated $\mathrm{m}-\mathrm{TiO}_{2}$ films with spin-coating (Figures S7 and $4 \mathrm{~b}$ ). Finally, annealing at $100^{\circ} \mathrm{C}$ promotes the evaporation of excess MeOAc, which improves the cohesion between $\mathrm{TiO}_{2}$ and QDs. In order to exclude possible influence of acetate, a saturated MeOAc solution of sodium acetate $(\mathrm{NaOAc})$ was also employed to modify the $\mathrm{m}-\mathrm{TiO}_{2}$ films. The $J-V$ curve shown in Figure S8 reveals that acetate has negligible influence on the PCE compared with Figure S7, which further confirms the significance of $\mathrm{Cs}^{+}$ions in the process. The scheme shown in Figure 2e illustrates the incorporation of QD into the mesoporous layer induced by the Cs-treatment: Without the Cs-treatment, $\mathrm{CsPbI}_{3}$ QDs can be easily adsorbed on the surface of $\mathrm{m}-\mathrm{TiO}_{2}$, which would block the $\mathrm{TiO}_{2}$ mesoporous framework. As a result, QDs will accumulate on the surface of $\mathrm{m}-\mathrm{TiO}_{2}$, and no QDs can migrate into the mesoporous layer. In contrast, the introducing of $\mathrm{CsOAc/MeOAc} \mathrm{solution} \mathrm{will} \mathrm{reduce} \mathrm{the} \mathrm{adsorption} \mathrm{energy} \mathrm{of} \mathrm{QDs}$ on the surface of $\mathrm{TiO}_{2}$ and facilitate the incorporation of QD into the mesoporous layer. Moreover, the $\mathrm{Cs}^{+}$ions induced by the Cs-treatment can further passivate the surface of QDs and promote the charge transfer from the QDs to $\mathrm{TiO}_{2}$.

Steady-state photoluminescence (PL) spectra of $\mathrm{CsPbI}_{3}$ QDs dispersed in octane and of various $\mathrm{TiO}_{2} / \mathrm{CsPbI}_{3}$ QD films are shown in Figure S9. A comparison of the solid-state samples shows a marked decrease of the PL intensity when going from untreated m- or c- $\mathrm{TiO}_{2}$ to Cstreated $\mathrm{m}-\mathrm{TiO}_{2}$. This indicates that the injection of photo-generated electrons from the QDs into $\mathrm{TiO}_{2}$ is most efficient in the case of the Cs-m- $\mathrm{TiO}_{2} / \mathrm{CsPbI}$ QD film. Furthermore, transient 
absorption (TA) spectroscopy was used to study the carrier kinetics within the $\mathrm{TiO}_{2} / \mathrm{QD}$ film. Figure 3 shows the TA kinetics of the $\mathrm{CsPbI}_{3}$ QDs dispersed in octane and of various $\mathrm{TiO}_{2} / \mathrm{CsPbI}_{3}$ QDs films, which were recorded $5 \mathrm{ps}$ after band gap excitation at $692 \mathrm{~nm}$. One should note that the pump light intensity was fixed at $\sim 1 \mu \mathrm{J} / \mathrm{cm}^{2}$, in order to achieve results with negligible influence of Auger recombination. ${ }^{30}$ The TA kinetics can be well fitted to a singleexponential function $\left(y(t)=A_{0} \exp \left(\frac{-t}{\tau}\right)+y_{0}\right)$, where the time constants for the QDs, m$\mathrm{TiO}_{2} / \mathrm{QDs}, \mathrm{c}-\mathrm{TiO}_{2} / \mathrm{QDs}$, and $\mathrm{Cs}-\mathrm{m}-\mathrm{TiO}_{2} / \mathrm{QDs}$ are found to be $462,135,91$, and $51 \mathrm{ps}$, respectively. The TA decay in the $\mathrm{TiO}_{2} / \mathrm{QDs}$ films is faster than in QDs colloidal solution, i.e., photo-induced electron-hole pairs in $\mathrm{CsPbI}_{3}$ QDs are separated by the films, and the electrons are transferred to the $\mathrm{TiO}_{2}$ ETM. Furthermore, the electron injection rate constants $k_{\left(Q D_{S} / \mathrm{TiO}_{2}\right)}$ can be calculated using $k_{\left(Q D S / T i O_{2}\right)}=\frac{1}{\tau_{\left(Q D S+T i O_{2}\right)}}-\frac{1}{\tau_{Q D S}}{ }^{40}$ and are found to be $0.52 \times 10^{10} \mathrm{~s}^{-1}$, $0.88 \times 10^{10} \mathrm{~s}^{-1}$, and $1.74 \times 10^{10} \mathrm{~s}^{-1}$ for $\mathrm{m}-\mathrm{TiO}_{2} / \mathrm{QDs}, \mathrm{c}-\mathrm{TiO}_{2} / \mathrm{QDs}$, and $\mathrm{Cs}-\mathrm{m}-\mathrm{TiO}_{2} / \mathrm{QDs}$ films, respectively. Summarizing, the electron injection rate in the $\mathrm{Cs}-\mathrm{m}-\mathrm{TiO}_{2} / \mathrm{QDs}$ film is approximately a factor 2 higher than that in the $\mathrm{c}-\mathrm{TiO}_{2} / \mathrm{QDs}$ film, and a factor 3 higher than that in the $\mathrm{m}-\mathrm{TiO}_{2} / \mathrm{QDs}$ film.
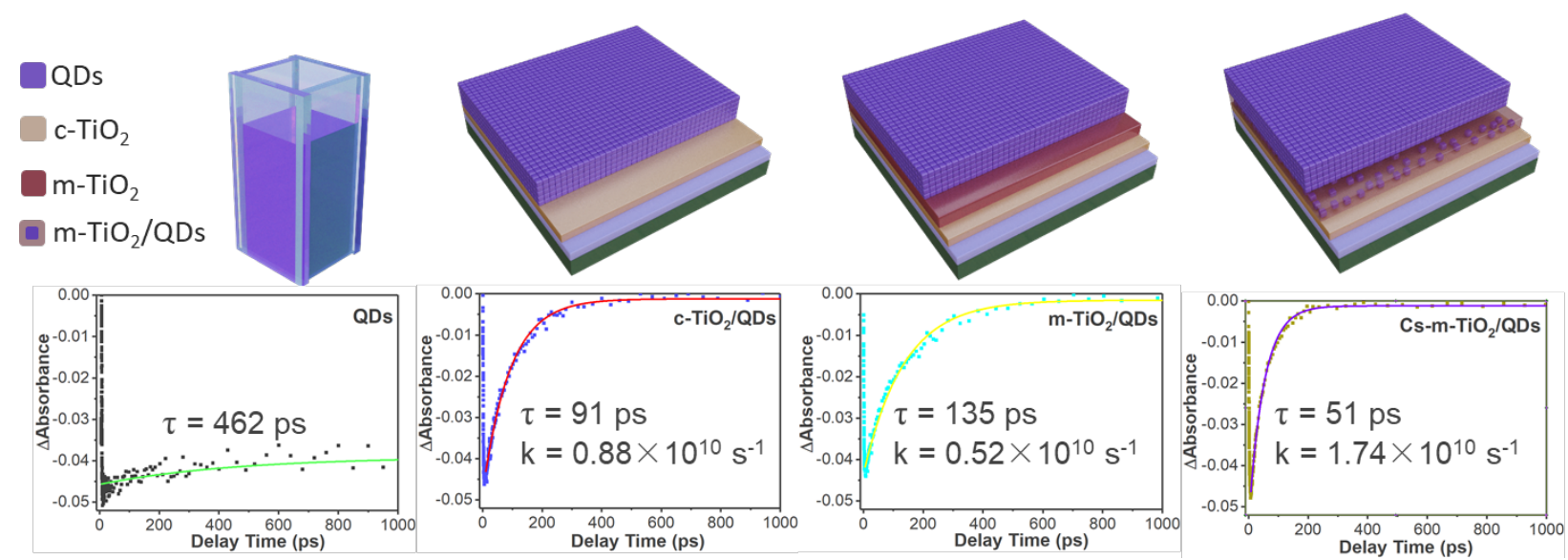

Figure 3. Schematic representation and TA kinetics of $\mathrm{CsPbI}_{3}$ QDs dispersed in octane and 
various $\mathrm{TiO}_{2} / \mathrm{CsPbI}_{3} \mathrm{QD}$ films.

The obtained Cs-m- $\mathrm{TiO}_{2}$ films were employed as ETMs for the fabrication of $\mathrm{CsPbI}_{3}$ QDbased solar cells. A histogram of the PCE values obtained from 50 devices using $\mathrm{Cs}-\mathrm{m}-\mathrm{TiO}_{2}$ films is shown in Figure S10. One can see that even though some of the devices exhibit comparably high performance $(\sim 13 \%)$, the reproducibility of the PSCs is not very good and most cells are in the $11 \%$ range. Figure $\mathrm{S} 11$ a shows a top-view $\mathrm{SEM}$ image of the $\mathrm{m}-\mathrm{TiO}_{2}$ film. It is clear that the mesoporous structure is irregular, and a significant undulance can be observed. AFM measurements (Figure S11b) demonstrate that the film morphology is governed by the macroscopic roughness of the $\mathrm{m}-\mathrm{TiO}_{2}$ structure and QD treatment is only visible as a finer texture on top of the $\mathrm{TiO}_{2}$ grains. The obtained value of surface roughness for the analyzed film is as high as $48.8 \mathrm{~nm}$, which leads inevitably to an irregular QD-coated $\mathrm{m}-\mathrm{TiO}_{2}$ film (surface roughness: $38.4 \mathrm{~nm}$, Figure S11c). These are clearly not ideal conditions for the subsequent deposition of the HTM layer and metal electrode and the high surface irregularity can thus be considered as an important factor at the origin of the low reproducibility of the PSCs. The high surface roughness of the pristine $\mathrm{m}-\mathrm{TiO}_{2}$ film is related to the spin-coating process used for its formation. We succeeded in flattening the $\mathrm{m}-\mathrm{TiO}_{2}$ film considerably by employing a post-deposition ethanol-environment smoothing procedure. Briefly, the freshly prepared $\mathrm{m}-\mathrm{TiO}_{2}$ films were kept for $3 \mathrm{~min}$ in a sealed box containing a few drops of ethanol at room temperature and subsequently heated at open air for $7 \mathrm{~min}$ at $125{ }^{\circ} \mathrm{C}$. The ethanol atmosphere could reduce surface stress and relieve the surface irregularity of the $\mathrm{m}-\mathrm{TiO}_{2}$ films. ${ }^{41}$ Figure S11d and S11e show SEM and AFM images of top-views of the smoothed m$\mathrm{TiO}_{2}$ films (s-m- $\mathrm{TiO}_{2}$ ). Their surfaces are much more homogeneous and flat than those of the $\mathrm{m}-\mathrm{TiO}_{2}$ films (Figure $\mathrm{S} 11 \mathrm{a}$ and $\mathrm{S} 11 \mathrm{~b}$ ), resulting in a surface roughness of the s-m- $-\mathrm{TiO}_{2}$ film of $9.6 \mathrm{~nm}$. As in the non-smoothed films, the planarity after QD deposition becomes even better, with a surface roughness of $6.2 \mathrm{~nm}$.

Finally, the Cs-s-m- $\mathrm{TiO}_{2} / \mathrm{QD}$ films were used to fabricate PSCs, and the schematic device 
structure is shown in Figure 4a. Out of 50 devices all exhibited PCE values higher than 13\%, which suggests that the ethanol-environment smoothing process could greatly enhance the performance of the PSCs (Figure S12). Importantly, the histograms of the solar cell characteristics also show that the reproducibility of PSC device fabrication is strongly improved. The characteristics of the best performing $\mathrm{CsPbI}_{3}$ QDs-based solar cell are displayed in Figure $4 b$ and 4c. It exhibited a PCE of $14.32 \%$ (reverse-scan), which represents one of the highest performances for all-inorganic lead halide QD-based PSCs and for QD-based solar cells in general. Notably, the $J_{S C}$ value reaches up to $17.77 \mathrm{~mA} \mathrm{~cm}{ }^{-2}$, which is the highest reported value for QD-based PSCs. Moreover, the device exhibits a stabilized power output (SPO, measured at $0.84 \mathrm{~V}$ ) of $13.87 \%$. This device also exhibits maximum external quantum efficiency (EQE) of $\sim 92 \%\left(J_{\text {Int }}=17.09 \mathrm{~mA} \mathrm{~cm}^{-2}\right)$, as shown in Figure 4c. The band gap of the QD film calculated from the EQE spectrum is $1.75 \mathrm{eV}$, which is consistent with previous reports. $^{12}$ Finally, environmental stability studies showed that unencapsulated devices maintained $90 \%$ of the initial PCE after being kept for $100 \mathrm{~h}$ under ambient conditions (cf. Figure S13). 
(a)

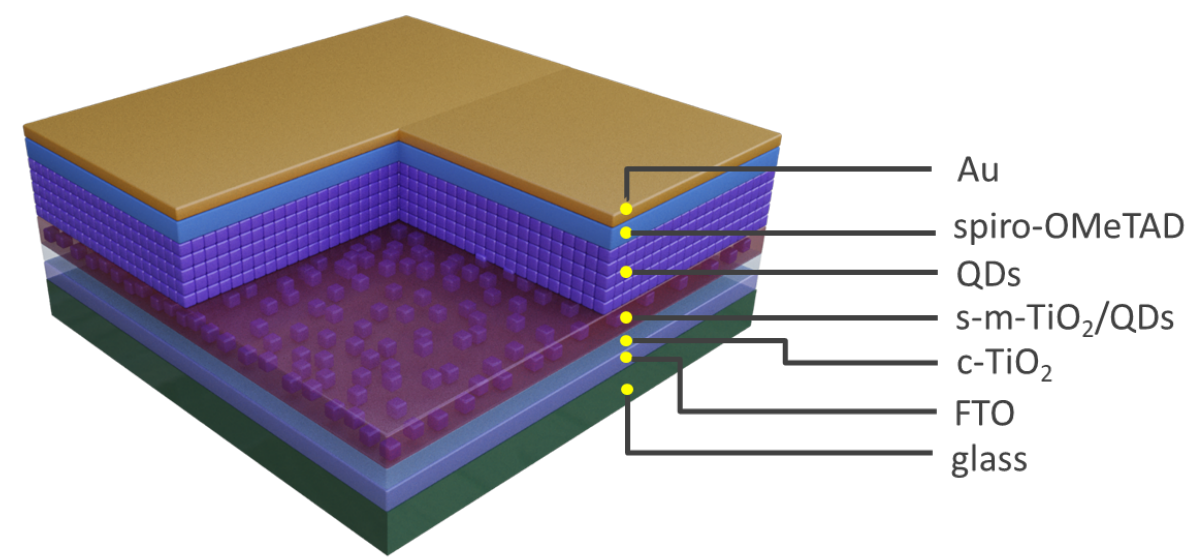

(b)

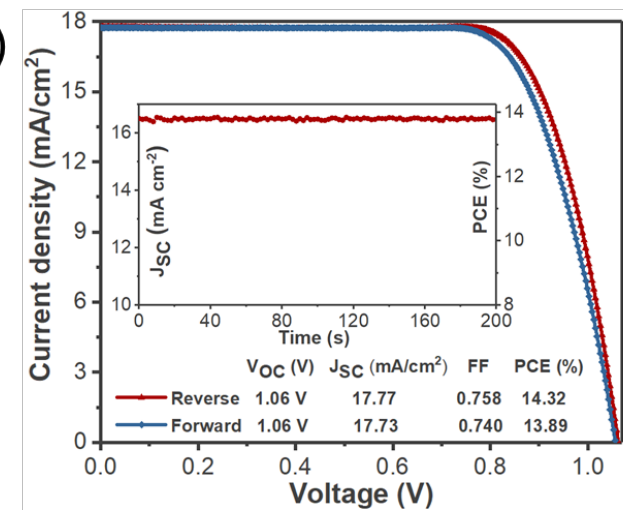

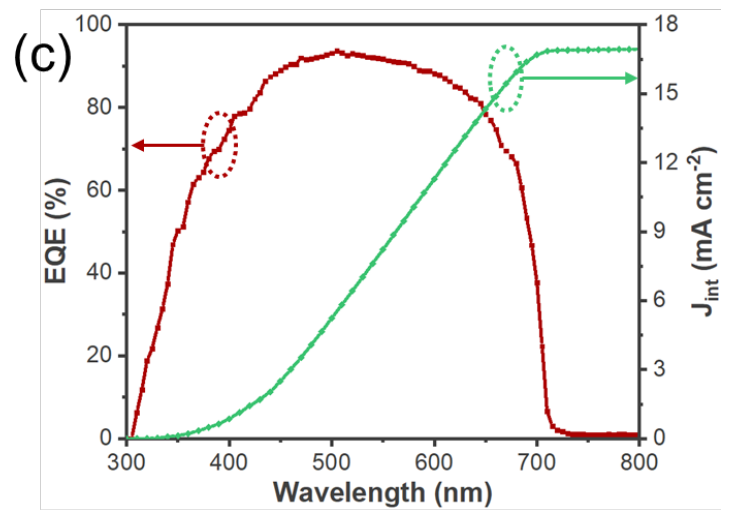

Figure 4. (a) Schematic view of the $\mathrm{CsPbI}_{3}$ QD-based PSC with mesoporous structure. (b) $J-V$ curve, stable power output (measured at $0.84 \mathrm{~V}$ ), and parameters of the champion device. (c) EQE spectrum (red, left ordinate) and integrated current density (green, right ordinate) of the device in panel (b).

A series of additional characterizations were performed to achieve a more detailed insight into the physical effects induced by the Cs-treatment. First, the trap densities of $\mathrm{TiO}_{2} /$ perovskite layers with or without Cs-treatment were measured using the space-charge limited current (SCLC) method. ${ }^{42-43}$ Electron-only devices with a structure of $\mathrm{ITO} / \mathrm{TiO}_{2} / \mathrm{CsPbI}_{3}$ QDs/PCBM/Ag were fabricated, and the corresponding dark current-voltage characteristics are shown in Figure 5a. The trap densities $\left(N_{\text {trap }}\right)$ were calculated according to the equation $N_{\text {trap }}=$ $2 \varepsilon_{r} \varepsilon_{0} V_{T F L} / e L^{2}$ where $\varepsilon_{r}$ and $\varepsilon_{0}$ are the relative dielectric constant and vacuum permittivity, respectively, and $e$ represents the elementary charge. The obtained values are $1.59 \times 10^{15} \mathrm{~cm}^{-3}$ (with Cs-treatment) and $4.68 \times 10^{15} \mathrm{~cm}^{-3}$ (without Cs-treatment) suggesting an effective passivation of trap states induced by the Cs-treatment. Second, the recombination kinetics 
within the device was further characterized by investigating the light-intensity dependent $J-V$ properties, as shown in Figure 5b. A slope, expressed by nKT/q (where n, K, T, and q represent the ideality factor, Boltzmann constant, absolute temperature, and elementary charge, respectively) larger than 1 reveals the occurrence of trap-assisted recombination. Devices with lower trap state density possess smaller slopes, ${ }^{20}$ which is the case for a typical Cs-treated device $(1.145 \mathrm{KT} / \mathrm{q})$ in comparison with an untreated device $(1.248 \mathrm{KT} / \mathrm{q})$, further confirming the reduction of trap-assisted recombination induced by the Cs-treatment. Third, the interfacial charge transfer and recombination was also investigated, as shown in Figure 5c. The Nyquist plots reveal that the Cs-treated device exhibits a smaller transfer resistance $\left(R_{t r}, 15.99 \Omega\right)$ and larger recombination resistance $\left(R_{r e c}, 3139 \Omega\right)$ than that of the untreated device $\left(R_{t r}=41.96 \Omega\right.$, $R_{\text {rec }}=2508 \Omega$ ), indicative of enhanced charge transfer and reduced charge recombination processes in the Cs-treated device. Finally, time-resolved photoluminescence (TRPL) is applied to further evaluate the charge transfer processes in the different devices. The carrier lifetime of Cs-treated devices (1.37 ns, Table S1) is much shorter than that of untreated devices (3.79 ns), which further suggests the more efficient charge transfer in the former. Therefore, we can conclude that the Cs-treatment is an effective strategy to passivate trap states and enhance the charge transfer in $\mathrm{CsPbI}_{3}$ QDs-based solar cells. 

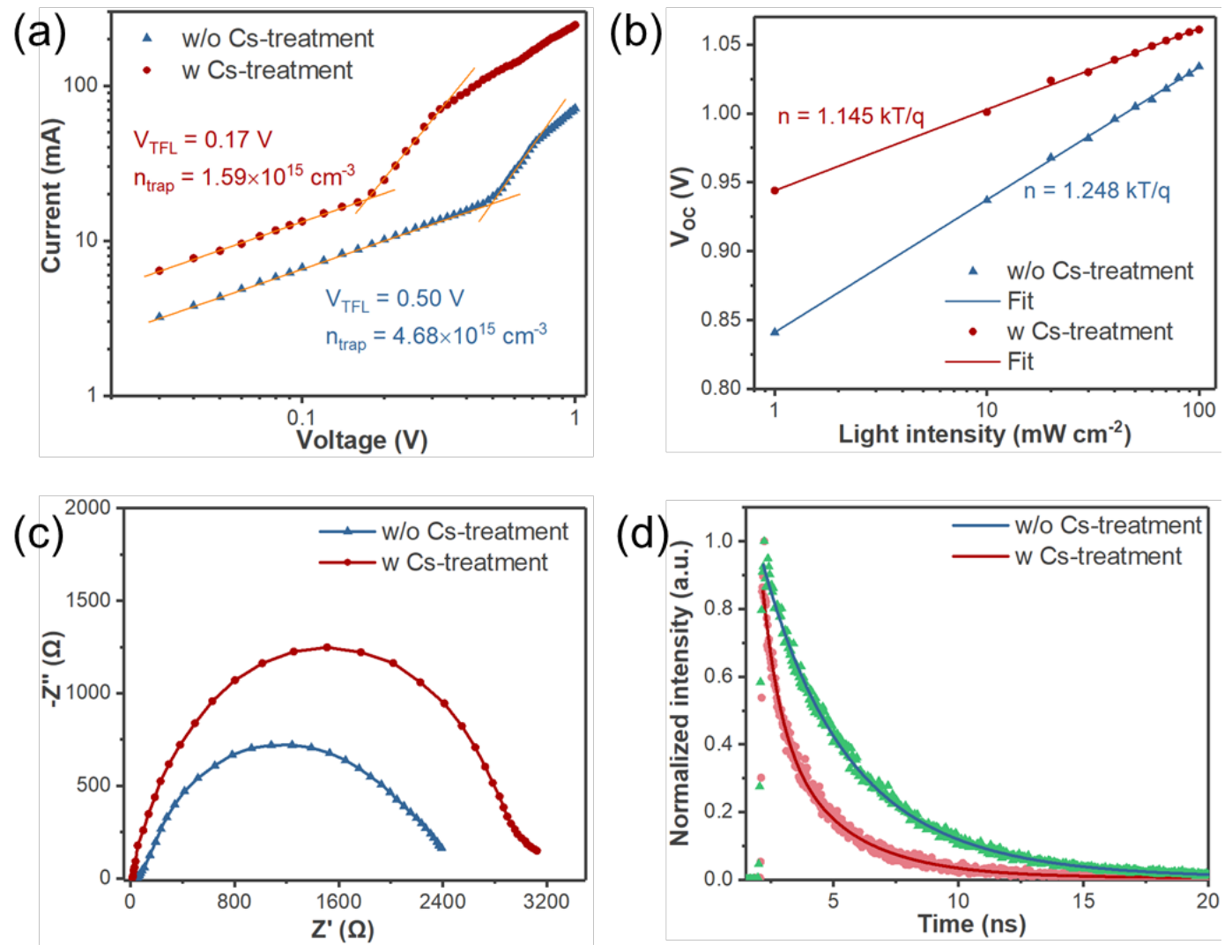

Figure 5. Device characteristics of the $\mathrm{CsPbI}_{3}$ QD films with or without Cs-treatment: (a) space-charge limited current (SCLC) versus voltage; (b) light intensity versus open circuit voltage; (c) Nyquist plots; (d) TRPL plots.

\section{Conclusion}

In summary, for the first time highly efficient $\mathrm{CsPbI}_{3}$ QD-based PSCs using mesoscopic $\mathrm{TiO}_{2}$ as the ETM were demonstrated. Interface engineering with $\mathrm{MeOAc} / \mathrm{CsOAc}$ not only favors the incorporation of $\mathrm{CsPbI}_{3}$ QDs into the mesoporous $\mathrm{TiO}_{2}$ structure, but also results in a well-defined contact between the $\mathrm{m}-\mathrm{TiO}_{2} \mathrm{ETM}$ and the QD layer, which greatly enhances charge separation and electron injection rates. We have also shown that treatment with MeOAc/MAI solution can lead to similar improvements as with MeOAc/CsOAc, demonstrating the versatility of the approach. Additionally, an ethanol-environment smoothing route was developed to drastically reduce the surface roughness of mesoscopic $\mathrm{TiO}_{2}$ films and produce a planar $\mathrm{CsPbI}_{3} \mathrm{QD}$ capping layer. The obtained devices exhibit PCE values exceeding $13 \%$ with a very good reproducibility. The best device reached a PCE of $14.32 \%$ (reverse scan) 
with a $J_{S C}$ of $17.77 \mathrm{~mA} \mathrm{~cm}^{-2}$, which is the highest value reported for QD-based PSCs and for QD-based solar cells in general. The strategy of combining different approaches to engineer the interface from the atomic to the nanometer scale can be generalized to improve the performances not only of all-inorganic lead halide PSCs, but also of solar cells sensitized with other types of QDs, in particular Pb-free perovskites, which are under intense current research. ${ }^{44}$ With a band gap of $1.75 \mathrm{eV}$, the $\mathrm{CsPbI}_{3}$ QD absorber is also ideally suited for integration into tandem cells with silicon. 


\section{Experimental Section}

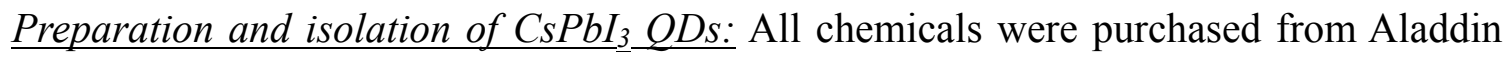
and used as received. $2 \mathrm{mmol}$ of $\mathrm{PbI}_{2}(0.922 \mathrm{~g}, 99.9 \%)$ and $20 \mathrm{~mL}$ of 1-octadecene (ODE, technical grade, $90 \%$ ) were mixed in a three-neck flask and heated to $120^{\circ} \mathrm{C}$ in Ar. Thereafter, $2.5 \mathrm{~mL}$ of oleylamine (OLA, $80-90 \%$ ) and $2.5 \mathrm{~mL}$ of oleic acid (OA, AR) were added to the above solution. The mixture was held at this temperature for $30 \mathrm{~min}$ to dissolve $\mathrm{PbI}_{2}$ and remove $\mathrm{H}_{2} \mathrm{O}$ and $\mathrm{O}_{2}$. Subsequently, $0.8 \mathrm{~mL}$ of a $0.5 \mathrm{M}$ Cs-OA solution $(5 \mathrm{mmol}$ cesium acetate $(\mathrm{CsOAc}$, 99.9\% metals basis) dissolved in $10 \mathrm{~mL} \mathrm{OA}$ at atmosphere) was swiftly injected into the reaction mixture at $180^{\circ} \mathrm{C}$. The reaction was ended by cooling down the mixture to room temperature after $5 \mathrm{~s}$. The $\mathrm{CsPbI}_{3}$ QDs were purified by adding $3 \mathrm{~mL}$ of methyl acetate $(\mathrm{MeOAc}$, anhydrous $99.5 \%$ ) into $1 \mathrm{~mL}$ of the crude solution and centrifuging at $9000 \mathrm{rpm}$ for $3 \mathrm{~min}$. Then $1 \mathrm{~mL}$ of octane $(>99 \%)$ was added to re-disperse the precipitate after the supernatant was discarded. The QD-octane colloidal solution was centrifuged at $9000 \mathrm{rpm}$ for $3 \mathrm{~min}$ a second time to remove any insoluble aggregates. The above isolation process was repeated between one and three times to yield $\mathrm{CsPbI}_{3}$ QDs with the desired surface ligand density (cf. Supporting Information).

Device Fabrication: FTO substrates $\left(12 \Omega \mathrm{sq}^{-1}\right)$ were cleaned by sonicating in deionized water and ethanol for $15 \mathrm{~min}$, and the substrates were subsequently dried with compressed air and treated with UV ozone. A compact- $\mathrm{TiO}_{2}\left(\mathrm{c}-\mathrm{TiO}_{2}\right)$ blocking layer of $30 \mathrm{~nm}$ thickness was deposited on the $1 \times 2 \mathrm{~cm}^{2}$ cleaned FTO substrates from a $0.5 \mathrm{M} \mathrm{TiCl}_{4}(99.9 \%)$ deionized water solution at $70^{\circ} \mathrm{C}$ and annealed at $450^{\circ} \mathrm{C}$ for $60 \mathrm{~min}$. Mesoporous $\mathrm{TiO}_{2}\left(\mathrm{~m}-\mathrm{TiO}_{2}\right)$ pastes were prepared by following the procedure outlined in Ref. $29 .{ }^{35} \mathrm{An} \mathrm{m}-\mathrm{TiO}_{2}$ layer of approximately $200 \mathrm{~nm}$ thickness was deposited by spin-coating at $3000 \mathrm{rpm}$ for $20 \mathrm{~s}$. An ethanol-environment smoothing route was used to flatten the $\mathrm{m}-\mathrm{TiO}_{2}$ film as follows: After spin-coating the $\mathrm{m}-\mathrm{TiO}_{2}$ film was placed in a clean, sealed box with several drops of ethanol for $3 \mathrm{~min}$ at room temperature, followed by drying in open air for $7 \mathrm{~min}$ at $125{ }^{\circ} \mathrm{C}$ (named s-m- $\mathrm{TiO}_{2}$ ). Finally, a 
$450^{\circ} \mathrm{C}$ heat treatment for $1 \mathrm{~h}$ was used to sinter and to remove organics from the $\mathrm{TiO}_{2}$ films. Two types of substrates with different morphologies $\left(\mathrm{c}-\mathrm{TiO}_{2}\right.$ or $\left.\mathrm{m}-\mathrm{TiO}_{2}\right)$ were used for Cstreatment, which were named $\mathrm{Cs}-\mathrm{c}-\mathrm{TiO}_{2}$ or $\mathrm{Cs}-\mathrm{m}-\mathrm{TiO}_{2}$, respectively. $100 \mu \mathrm{L}$ saturated $\mathrm{CsOAc} / \mathrm{MeOAc}$ solution was dropped on the $\mathrm{TiO}_{2}$-coated substrates for $10 \mathrm{~s}$ before spin-coating at $2000 \mathrm{rpm}$ for $10 \mathrm{~s}$. Subsequently, QDs $(\sim 70 \mathrm{mg} / \mathrm{mL}$ in octane) were dropped onto these substrates for $20 \mathrm{~s}$ before spin-coating at $1000 \mathrm{rpm} 10 \mathrm{~s}$, followed by $2000 \mathrm{rpm} 10 \mathrm{~s}$. The QD spin-coating process was repeated 2-4 times to yield a QD film with $200 \mathrm{~nm}$ thickness. A $5 \mathrm{~min}$ heat treatment at $100^{\circ} \mathrm{C}$ was applied before spin-coating the HTM. The HTM was prepared by spin-coating a saturated MeOAc/spiro-OMeTAD solution onto the film at $3000 \mathrm{rpm}$ for $30 \mathrm{~s}$. All the spin-coating processes were performed under ambient conditions. Finally, Au electrodes of $\sim 80 \mathrm{~nm}$ thickness were deposited by evaporation.

Characterization: A focused ion beam (FIB) system (FEI 3D Quanta Nanolab FIB/SEM) was used to fabricate the cross-sectional TEM lamellae. A Pt layer was pre-deposited in the target area to avoid destroying the PSCs before FIB cross-section preparation. The microstructures and chemical composition of the PSCs were examined with a transmission electron microscope (TEM) equipped with an energy dispersive spectroscopy (EDS) detector (FEI Tecnai G2 F20). SEM images were collected with a field emission scanning electron microscope (FESEM, Hitachi S-4800). An atomic force microscope (AFM) with ScanAsyst in air mode (Dimension Icon, Veeco Instruments/Bruker, Germany) was used to examine the surface structure of the $\mathrm{TiO}_{2} / \mathrm{QDs}$ films. TA data were gathered with a Clark MXR-2010 laser system. The $J-V$ data was gathered with a Keithley 2400 SMU (Keithley Instruments, USA) under excitation with a $300 \mathrm{~W}$ xenon lamp solar simulator (Newport 91160, USA). A calibrated reference solar cell (Newport, USA) was used to confirm the intensity of the lamp $\left(100 \mathrm{~mW} \cdot \mathrm{cm}^{-}\right.$ ${ }^{2}$ ). A forward bias to reverse bias with a scan rate of $200 \mathrm{mV} / \mathrm{s}$ (step size and delay time were set as $10 \mathrm{mV}$ and $10 \mathrm{~ms}$, respectively) was used to collect the $J-V$ data. A metal aperture (0.09 $\mathrm{cm}^{2}$ ) was used when the devices were illuminated. Stabilized power output was measured at a 
constant voltage corresponding to the voltage at the maximum power point of the $J-V$ curve $(0.82 \mathrm{~V})$. The $J-V$ curves were collected in ambient lab air. A Xenon lamp (150 W, Oriel) equipped with a monochromator was used to collect the EQE spectra. A Nicolet Nexus-670 Fourier transform infrared (FTIR) spectrometer was used to gather FTIR spectra. The fluorescence spectroscopy was excited with a $365 \mathrm{~nm}$ laser (RF-5301PC, Shimadzu, Japan). TRPL spectroscopy was performed with a FLS 980 fluorescence spectrometer. EIS data were collected using an Autolab PGSTAT320 N electrochemical workstation.

DFT Computation: The model was built based on the $\mathrm{TiO}_{2}(001)$ surface. ${ }^{45-47}$ Oxygen atoms are supposed to be terminal atoms when the surface is annealed at $500{ }^{\circ} \mathrm{C}$. The used QDs are stabilized by OA and OLA binding with their carboxyl and amino groups to the surface, respectively, while the alkyl chains are free to interact with the $\mathrm{TiO}_{2}(001)$ surface. To simplify the interaction between $\mathrm{m}-\mathrm{TiO}_{2}$ and the QDs, we calculated the adsorption capacity of $\mathrm{OA}$ and OLA.

We performed periodic density functional calculations using the Dmol3 4.4 program. ${ }^{48-49}$ A Perdew-Burke-Ernzerhof (PBE) general gradient approximation (GGA) was used to describe the exchange-correlation interactions. ${ }^{50}$ The double numeric quality basis set with polarization functions (DNP) was used. The inner electrons on the Ti atoms were kept frozen and replaced with an effective core potential (ECP), while other atoms in this study were treated with an allelectron calculation. A supercell of the $\mathrm{TiO}_{2}(001)$ surface was $15.27 \times 15.27 \times 58.08 \AA^{3}$, and Brillouin-zone integrations were performed using a $2 \times 2 \times 1$ Monkhorst-Pack grid. Fermi smearing of 0.005 hartree was used to accelerate convergence, and the real space cutoff was set to $5.3 \AA$ in order to improve the computational performance. The energy, force, and displacement convergence tolerance were $1 \times 10^{-5}$ hartree, $2 \times 10^{-3}$ hartree $/ \AA$, and $5 \times 10^{-3} \AA$, respectively. Several possible configurations of different adsorbates on $\mathrm{TiO}_{2}(001)$ were considered for optimization, and all of the optimized atomic structures presented in this paper were found to be the most stable configurations. 


\section{Acknowledgements}

This work is supported by the National Natural Science Foundation of China (No. 11674258, 51602305, 61875139, and 51702219), the 111 Project (No. B18038), Key projects of Natural Science Foundation of Hubei Province (No. 2019CFA044), the Fundamental Research Funds for the Central Universities (No. 2017II22GX), the Nature Science Foundation of Guangdong Province (No. 2018A030313401), the Science and Technology Innovation Commission of Shenzhen (No. JCYJ20170818141519879, JCYJ20170818141429525), Project funded by China Postdoctoral Science Foundation (No. 2018M633102, 2017M620383), Shenzhen Nanshan District Pilotage Team Program (LHTD20170006), and Australian Research Council (ARC, FT150100450, IH150100006, DP160104575, CE170100026 and CE170100039). We thank Centre for Materials Research and Analysis at Wuhan University of Technology (WUT) for the assistance on sample measurements and Dr. Wei Wei (WUT) for NMR measurements and analysis. P.R. acknowledges financial support from the French Research Agency ANR (grants SuperSansPlomb ANR-15-CE05-0023-01 and PERSIL ANR16-CE05-0019-02).

\section{Competing interests}

The authors declare no competing financial interests.

\section{Supporting Information}

TEM images of the $\mathrm{CsPbI}_{3}$ QDs, calculation of the surface ligand density, description of the NMR measurements, $J-V$ curves of control devices, STEM-EDS images of an untreated m$\mathrm{TiO}_{2} / \mathrm{CsPbI}_{3}$ film, FTIR and water contact angle measurements, AFM images and device statistics. 


\section{References}

1. Alivisatos, A. P., Semiconductor clusters, nanocrystals, and quantum dots. Science 1996, 271, 933-937.

2. Balazs, D. M.; Bijlsma, K. I.; Fang, H.-H.; Dirin, D. N.; Döbeli, M.; Kovalenko, M. V.; Loi, M. A., Stoichiometric control of the density of states in PbS colloidal quantum dot solids. Sci. Adv. 2017, 3, eaao1558.

3. Boles, M. A.; Ling, D.; Hyeon, T.; Talapin, D. V., The surface science of nanocrystals. Nat. Mater. 2016, 15, 141-153.

4. Ning, C.-Z.; Dou, L.; Yang, P., Bandgap engineering in semiconductor alloy nanomaterials with widely tunable compositions. Nat. Rev. Mater. 2017, 2, 17070.

5. Semonin, O. E.; Luther, J. M.; Choi, S.; Chen, H.-Y.; Gao, J.; Nozik, A. J.; Beard, M. C., Peak external photocurrent quantum efficiency exceeding $100 \%$ via MEG in a quantum dot solar cell. Science 2011, 334, 1530-1533.

6. Polman, A.; Knight, M.; Garnett, E. C.; Ehrler, B.; Sinke, W. C., Photovoltaic materials: Present efficiencies and future challenges. Science 2016, 352, aad4424-aad4424.

7. Sargent, E. H., Colloidal quantum dot solar cells. Nat. Photon. 2012, 6, 133-135.

8. Beard, M. C.; Midgett, A. G.; Hanna, M. C.; Luther, J. M.; Hughes, B. K.; Nozik, A. J., Comparing multiple exciton generation in quantum dots to impact ionization in bulk semiconductors: Implications for enhancement of solar energy conversion. Nano Lett. 2010, 10,3019-3027.

9. Sukhovatkin, V.; Hinds, S.; Brzozowski, L.; Sargent, E. H., Colloidal quantum-dot photodetectors exploiting multiexciton generation. Science 2009, 324, 1542-1544.

10. Protesescu, L.; Yakunin, S.; Bodnarchuk, M. I.; Krieg, F.; Caputo, R.; Hendon, C. H.; Yang, R. X.; Walsh, A.; Kovalenko, M. V., Nanocrystals of cesium lead halide perovskites $\left(\mathrm{CsPbX}_{3}, \mathrm{X}=\mathrm{Cl}, \mathrm{Br}\right.$, and $\left.\mathrm{I}\right)$ : Novel optoelectronic materials showing bright emission with wide color gamut. Nano Lett. 2015, 15, 3692-3696.

11. Liu, F.; Zhang, Y.; Ding, C.; Kobayashi, S.; Izuishi, T.; Nakazawa, N.; Toyoda, T.; Ohta, T.; Hayase, S.; Minemoto, T.; Yoshino, K.; Dai, S.; Shen, Q., Highly luminescent phase-stable $\mathrm{CsPbI}_{3}$ perovskite quantum dots achieving near $100 \%$ absolute photoluminescence quantum yield. ACS Nano 2017, 11, 10373-10383.

12. Abhishek Swarnkar; Ashley R. Marshall; Erin M. Sanehira; Boris D. Chernomordik; David T. Moore; Jeffrey A. Christians; Tamoghna Chakrabarti; Luther, J. M., Quantum dotinduced phase stabilization of $\alpha-\mathrm{CsPbI}_{3}$ perovskite for high-efficiency photovoltaics. Science 2016, 354, 92-95. 
13. Wang, Y.; Dar, M. I.; Ono, L. K.; Zhang, T.; Kan, M.; Li, Y.; Zhang, L.; Wang, X.; Yang, Y.; Gao, X.; Qi, Y.; Grätzel, M.; Zhao, Y., Thermodynamically stabilized $\beta-\mathrm{CsPbI}_{3}-$ based perovskite solar cells with efficiencies $>18 \%$. Science 2019, 365, 591-595.

14. Wu, L.; Chen, K.; Huang, W.; Lin, Z.; Zhao, J.; Jiang, X.; Ge, Y.; Zhang, F.; Xiao, Q.; Guo, Z.; Xiang, Y.; Li, J.; Bao, Q.; Zhang, H., Perovskite $\mathrm{CsPbX}_{3}$ : A promising nonlinear optical material and its applications for ambient all-optical switching with enhanced stability. $A d v$. Optical Mater. 2018, 6, 1800400.

15. Chen, K.; Wang, Y.; Liu, J.; Kang, J.; Ge, Y.; Huang, W.; Lin, Z.; Guo, Z.; Zhang, Y.; Zhang, H., In situ preparation of a $\mathrm{CsPBBr}_{3} /$ black phosphorus heterostructure with an optimized interface and photodetector application. Nanoscale 2019, 11, 16852-16859.

16. Wang, C.-T.; Chen, K.; Xu, P.; Yeung, F.; Kwok, H.-S.; Li, G., Fully chiral light emission from $\mathrm{CsPbX}_{3}$ perovskite nanocrystals enabled by cholesteric superstructure stacks. Adv. Funct. Mater. 2019, 29, 1903155.

17. Wang, Y.; Chen, K.; Hao, H.; Yu, G.; Zeng, B.; Wang, H.; Zhang, F.; Wu, L.; Li, J.; Xiao, S.; He, J.; Zhang, Y.; Zhang, H., Engineering ultrafast charge transfer in a bismuthene/perovskite nanohybrid. Nanoscale 2019, 11, 2637-2643.

18. Thapa, S.; Bhardwaj, K.; Basel, S.; Pradhan, S.; Eling, C. J.; Adawi, A. M.; Bouillard, J.-S. G.; Stasiuk, G. J.; Reiss, P.; Pariyar, A.; Tamang, S., Long-term ambient air-stable cubic $\mathrm{CsPbBr} 3$ perovskite quantum dots using molecular bromine. Nanoscale Advances 2019, 1, 3388-3391.

19. Sanehira, E. M.; Marshall, A. R.; Christians, J. A.; Harvey, S. P.; Ciesielski, P. N.; Wheeler, L. M.; Schulz, P.; Lin, L. Y.; Beard, M. C.; Luther, J. M., Enhanced mobility $\mathrm{CsPbI}_{3}$ quantum dot arrays for record-efficiency, high-voltage photovoltaic cells. Sci. Adv. 2017, 3, eaao4204.

20. Ling, X.; Zhou, S.; Yuan, J.; Shi, J.; Qian, Y.; Larson, B. W.; Zhao, Q.; Qin, C.; Li, F.; Shi, G.; Stewart, C.; Hu, J.; Zhang, X.; Luther, J. M.; Duhm, S.; Ma, W., 14.1\% CsPbI 3 perovskite quantum dot solar cells via cesium cation passivation. Adv. Energy Mater. 2019, 9, 1900721.

21. Yuan, J.; Ling, X.; Yang, D.; Li, F.; Zhou, S.; Shi, J.; Qian, Y.; Hu, J.; Sun, Y.; Yang, Y.; Gao, X.; Duhm, S.; Zhang, Q.; Ma, W., Band-aligned polymeric hole transport materials for extremely low energy loss $\alpha-\mathrm{CsPbI}_{3}$ perovskite nanocrystal solar cells. Joule 2018, 2, 24502463.

22. Chen, K.; Zhong, Q.; Chen, W.; Sang, B.; Wang, Y.; Yang, T.; Liu, Y.; Zhang, Y.; Zhang, $\mathrm{H}$., Short-chain ligand-passivated stable $\alpha \mathrm{CsPbI}_{3}$ quantum dot for all-inorganic perovskite 
solar cells. Adv. Funct. Mater. 2019, 29, 1900991.

23. Lee, M. M.; Teuscher, J.; Miyasaka, T.; Murakami, T. N.; Snaith, H. J., Efficient hybrid solar cells based on meso-superstructured organometal halide perovskites. Science 2012, 338, 643-647.

24. Kim, H. S.; Mora-Sero, I.; Gonzalez-Pedro, V.; Fabregat-Santiago, F.; Juarez-Perez, E. J.; Park, N. G.; Bisquert, J., Mechanism of carrier accumulation in perovskite thin-absorber solar cells. Nat. Commun. 2013, 4, 2242.

25. Xiong, L.; Qin, M.; Chen, C.; Wen, J.; Yang, G.; Guo, Y.; Ma, J.; Zhang, Q.; Qin, P.; Li, S.; Fang, G., Fully high-temperature-processed $\mathrm{SnO}_{2}$ as blocking layer and scaffold for efficient, stable, and hysteresis-free mesoporous perovskite solar cells. Adv. Funct. Mater. 2018, $28,1706276$.

26. Hairen Tan; Ankit Jain; Oleksandr Voznyy; Xinzheng Lan; F. Pelayo García de Arquer; James Z. Fan; Rafael Quintero-Bermudez; Mingjian Yuan; Bo Zhang; Yicheng Zhao; Fengjia Fan; Peicheng Li; Li Na Quan; Yongbiao Zhao; Zheng-Hong Lu; Zhenyu Yang; Sjoerd Hoogland; Sargent, E. H., Efficient and stable solution-processed planar perovskite solar cells via contact passivation. Science 2017, 355, 722-726.

27. Li, X.; Bi, D.; Yi, C.; Décoppet, J.-D.; Luo, J.; Zakeeruddin, S. M.; Hagfeldt, A.; Grätzel, M., A vacuum flash-assisted solution process for high-efficiency large-area perovskite solar cells. Science 2016, 353, 58-62.

28. Ummadisingu, A.; Steier, L.; Seo, J.-Y.; Matsui, T.; Abate, A.; Tress, W.; Grätzel, M., The effect of illumination on the formation of metal halide perovskite films. Nature 2017, 545, 208-212.

29. Kim, M.; Kim, G.-H.; Lee, T. K.; Choi, I. W.; Choi, H. W.; Jo, Y.; Yoon, Y. J.; Kim, J. W.; Lee, J.; Huh, D.; Lee, H.; Kwak, S. K.; Kim, J. Y.; Kim, D. S., Methylammonium chloride induces intermediate phase stabilization for efficient perovskite solar cells. Joule 2019, 3, 21792192.

30. Liu, F.; Zhang, Y.; Ding, C.; Toyoda, T.; Ogomi, Y.; Ripolles, T. S.; Hayase, S.; Minemoto, T.; Yoshino, K.; Dai, S.; Shen, Q., Ultrafast electron injection from photoexcited perovskite $\mathrm{CsPbI}_{3}$ QDs into $\mathrm{TiO}_{2}$ nanoparticles with injection efficiency near 99\%. J. Phys. Chem. Lett. 2018, 9, 294-297.

31. Akkerman, Q. A.; Gandini, M.; Di Stasio, F.; Rastogi, P.; Palazon, F.; Bertoni, G.; Ball, J. M.; Prato, M.; Petrozza, A.; Manna, L., Strongly emissive perovskite nanocrystal inks for high-voltage solar cells. Nat. Energy 2016, 2, 16194.

32. Hoffman, J. B.; Zaiats, G.; Wappes, I.; Kamat, P. V., CsPbBr 3 solar cells: Controlled film 
growth through layer-by-layer quantum dot deposition. Chem. Mater. 2017, 29, 9767-9774.

33. Li, J.; Xu, L.; Wang, T.; Song, J.; Chen, J.; Xue, J.; Dong, Y.; Cai, B.; Shan, Q.; Han, B.; Zeng, H., 50-fold EQE improvement up to $6.27 \%$ of solution-processed all-inorganic perovskite $\mathrm{CsPbBr}_{3}$ QLEDs via surface ligand density control. Adv. Mater. 2017, 29, 1603885. 34. Zhou, Y.; Game, O. S.; Pang, S.; Padture, N. P., Microstructures of organometal trihalide perovskites for solar cells: Their evolution from solutions and characterization. J. Phys. Chem. Lett. 2015, 6, 4827-4839.

35. Bu, T.; Wu, L.; Liu, X.; Yang, X.; Zhou, P.; Yu, X.; Qin, T.; Shi, J.; Wang, S.; Li, S.; Ku, Z.; Peng, Y.; Huang, F.; Meng, Q.; Cheng, Y.-B.; Zhong, J., Synergic interface optimization with green solvent engineering in mixed perovskite solar cells. Adv. Energy Mater. 2017, 7, 1700576.

36. Ogomi, Y.; Morita, A.; Tsukamoto, S.; Saitho, T.; Shen, Q.; Toyoda, T.; Yoshino, K.; Pandey, S. S.; Ma, T.; Hayase, S., All-solid perovskite solar cells with HOCO-R-NH${ }_{3}^{+} \mathrm{I}^{-}$anchorgroup inserted between porous titania and perovskite. J. Phys. Chem. C 2014, 118, 1665116659.

37. Grancini, G.; Roldán-Carmona, C.; Zimmermann, I.; Mosconi, E.; Lee, X.; Martineau, D.; Narbey, S.; Oswald, F.; De Angelis, F.; Graetzel, M., One-Year stable perovskite solar cells by 2D/3D interface engineering. Nature communications 2017, 8, 15684.

38. Shih, Y.; Wang, L.; Hsieh, H.; Lin, K., Enhancing the photocurrent of perovskite solar cells via modification of the $\mathrm{TiO}_{2} / \mathrm{CH}_{3} \mathrm{NH}_{3} \mathrm{PbI}_{3}$ heterojunction interface with amino acid. $J$. Mater. Chem. A 2015, 3, 9133-9136.

39. Pan, J.; Shang, Y.; Yin, J.; De Bastiani, M.; Peng, W.; Dursun, I.; Sinatra, L.; El-Zohry, A. M.; Hedhili, M. N.; Emwas, A.-H.; Mohammed, O. F.; Ning, Z.; Bakr, O. M., Bidentate ligand-passivated $\mathrm{CsPbI}_{3}$ perovskite nanocrystals for stable near-unity photoluminescence quantum yield and efficient red light-emitting diodes. J. Am. Chem. Soc. 2018, 140, 562-565. 40. Peng, Z.; Liu, Y.; Zhao, Y.; Shu, W.; Chen, K.; Bao, Q.; Chen, W., Efficiency enhancement of $\mathrm{TiO}_{2}$ nanodendrite array electrodes in $\mathrm{CuInS}_{2}$ quantum dot sensitized solar cells. Electrochim. Acta 2013, 111, 755-761.

41. Ito, S.; Chen, P.; Comte, P.; Nazeeruddin, M. K.; Liska, P.; Péchy, P.; Grätzel, M., Fabrication of screen-printing pastes from $\mathrm{TiO}_{2}$ powders for dye-sensitised solar cells. Prog. Photovolt. Res. Appl. 2007, 15, 603-612.

42. Chen, J.; Zhao, X.; Kim, S. G.; Park, N. G., Multifunctional chemical linker imidazoleacetic acid hydrochloride for $21 \%$ efficient and stable planar perovskite solar cells. Adv. Mater. 2019, 31, 1902902. 
43. Liu, S. C.; Li, Z.; Yang, Y.; Wang, X.; Chen, Y. X.; Xue, D. J.; Hu, J. S., Investigation of oxygen passivation for high-performance all-inorganic perovskite solar cells. J. Am. Chem. Soc. 2019, 141, 18075-18082.

44. Aldakov, D.; Reiss, P., Safer-by-design fluorescent nanocrystals: Metal halide perovskites vs semiconductor quantum dots. J. Phys. Chem. C 2019, 123, 12527-12541.

45. Etgar, L.; Gao, P.; Xue, Z.; Peng, Q.; Chandiran, A. K.; Liu, B.; Nazeeruddin, M. K.; Gratzel, M., Mesoscopic $\mathrm{CH}_{3} \mathrm{NH}_{3} \mathrm{PbI}_{3} / \mathrm{TiO}_{2}$ heterojunction solar cells. J. Am. Chem. Soc. 2012, 134, 17396-17399.

46. Mei, A.; Li, X.; Liu, L.; Ku, Z.; Liu, T.; Rong, Y.; Xu, M.; Hu, M.; Chen, J.; Yang, Y.; Grätzel, M.; Han, H., A hole-conductor-free, fully printable mesoscopic perovskite solar cell with high stability. Science 2014, 345, 295-298.

47. Feng, H. J.; Paudel, T. R.; Tsymbal, E. Y.; Zeng, X. C., Tunable optical properties and charge separation in $\mathrm{CH}_{3} \mathrm{NH}_{3} \mathrm{Sn}_{\mathrm{x}} \mathrm{Pb}_{1-\mathrm{x}} \mathrm{I}_{3} / \mathrm{TiO}_{2}$-based planar perovskites cells. J. Am. Chem. Soc. 2015, 137, 8227-8236.

48. Delley, B., An all-electron numerical method for solving the local density functional for polyatomic molecules. J. Chem. Phys. 1990, 92, 508-517.

49. Delley, B., From molecules to solids with the DMol3 approach. J. Chem. Phys. 2000, $113,7756-7764$.

50. Perdew, J. P.; Burke, K.; Ernzerhof, M., Generalized gradient approximation made simple. Phys. Rev. Lett. 1996, 77, 3865.

TOC graphic:

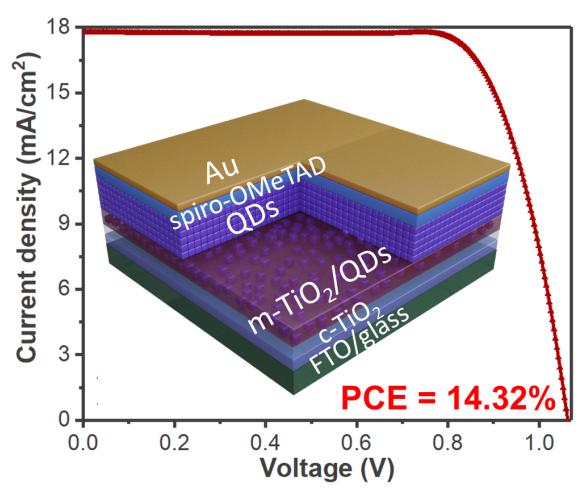

